\title{
Frequency of occurrence
}
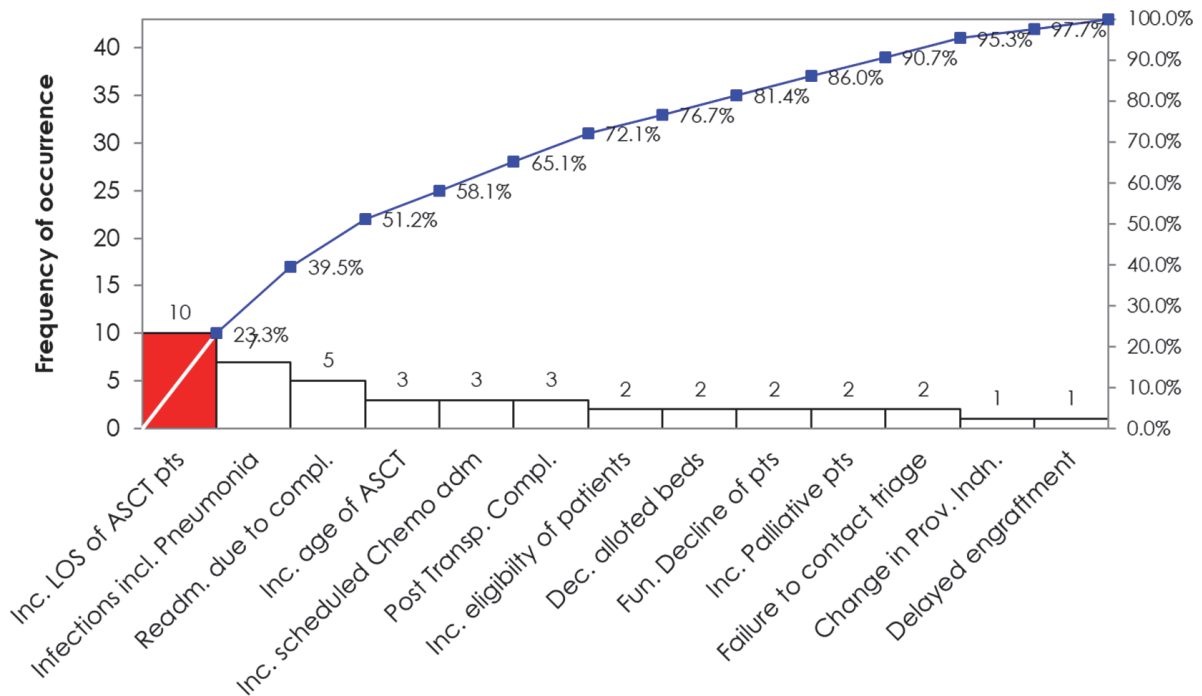

Root Causes of Inc.LOS in Hem C7 pts

Abstract 8 Figure 3 Pareto chart

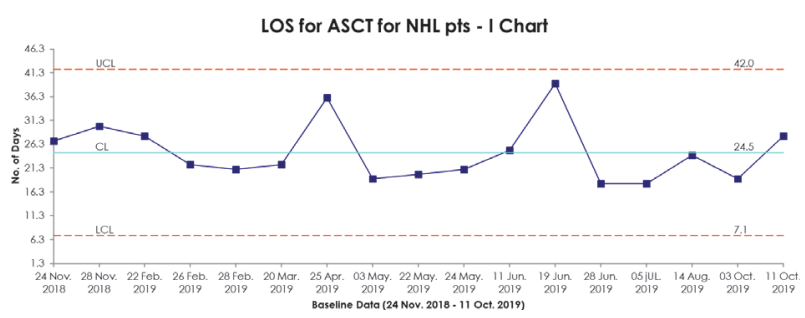

Abstract 8 Figure 4 LOS for ASCT for NHL patients - I Chart

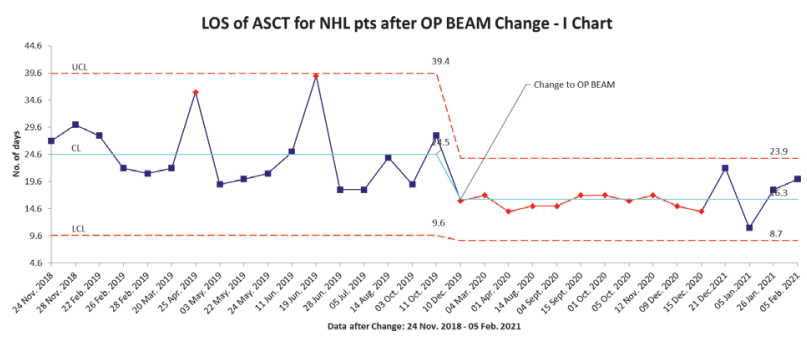

Abstract 8 Figure 5 LOS for ASCT for NHL patients after OP BEAM Change - I Chart
Conclusions Increase in the capacity for ASCT by decreasing the LOS by change of IP Conditioning Chemotherapy to OP setting is possible and feasible in QI framework.

\section{USING THE QI ESSENTIALS TOOLKIT TO ASSESS RISK, DRIVE AND SUSTAIN IMPROVEMENT IN MEDICATION SAFETY}

Mouna Ayoub Bahsoun, Anya Neidig. Intermountain Primary Children's Hospital

\subsection{6/bmjoq-2021-|HI.9}

Background Barcode-assisted medication administration (BCMA) is an evidence based practice to reduce medication administration errors; however, compliance rates with the use of this technology sometimes vary between different healthcare workers. Improving BCMA compliance benefits healthcare organizations in their efforts towards Zero Harm.

Objectives Achieve less than 2\% BCMA overrides at a pediatric hospital, within a 12 months' timeframe.

Methods To improve BCMA adherence across all disciplines, the IHI's QI Essentials Toolkit was used to guide an

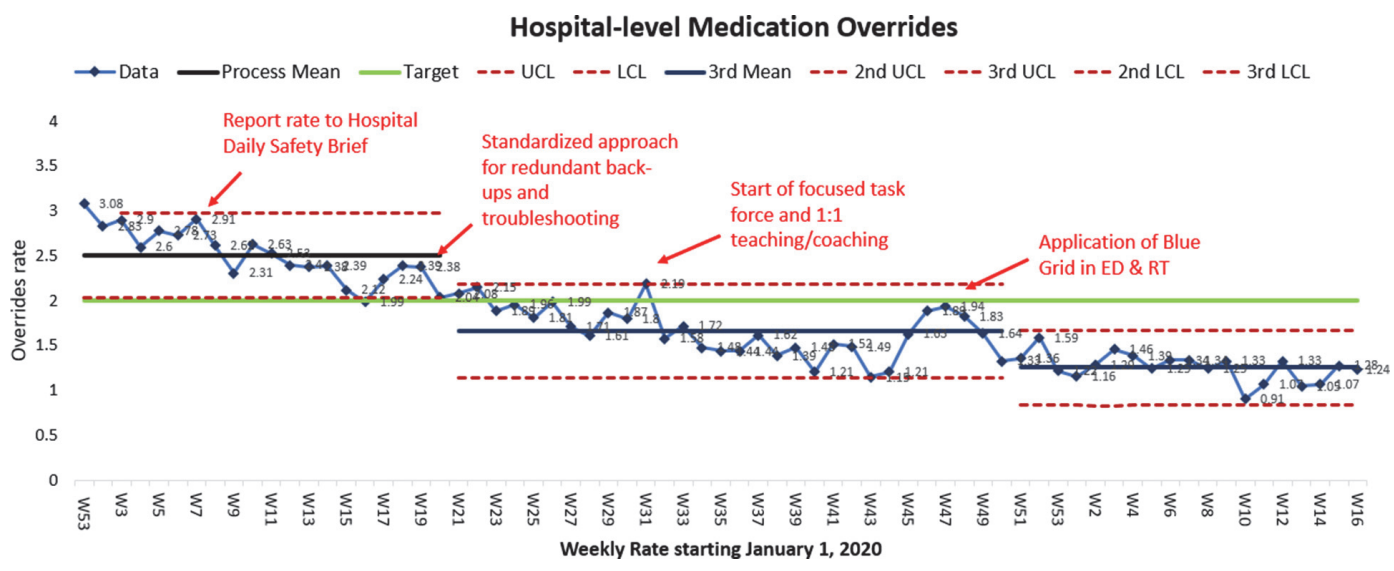

Abstract 9 Figure 1 Hospital-wide medication overrides 


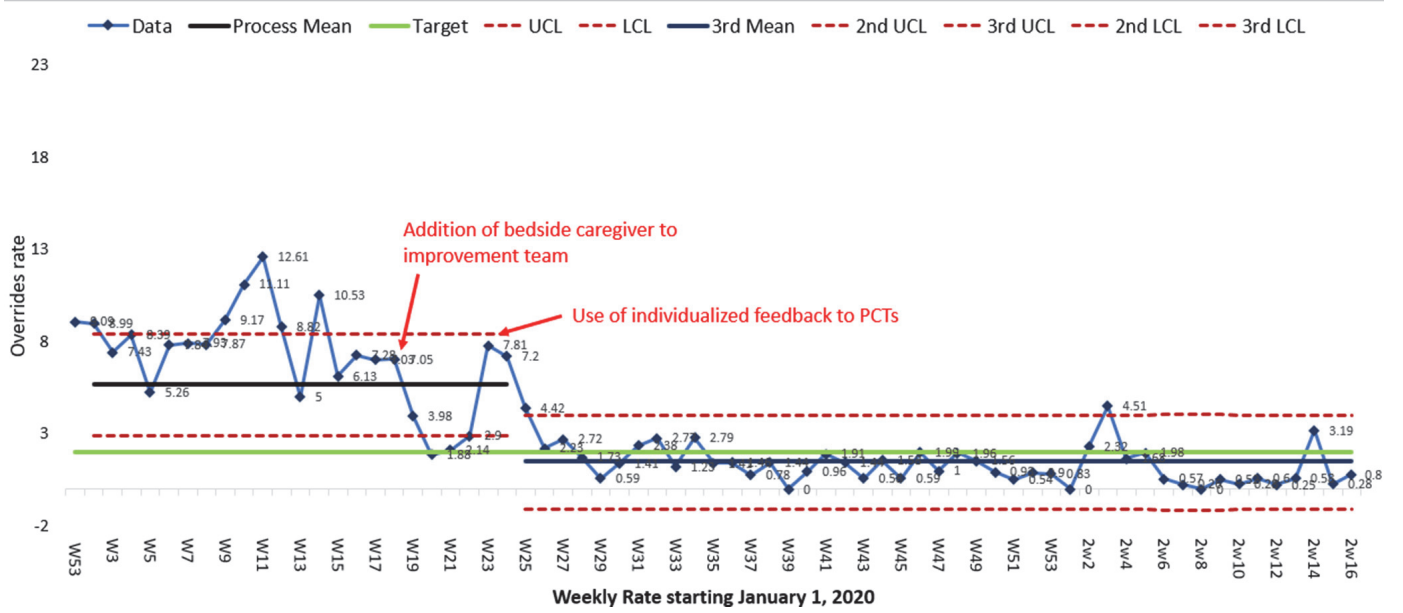

Abstract 9 Figure 2 Imaging - medication overrides

\begin{tabular}{|c|c|c|c|c|c|c|}
\hline \multirow{2}{*}{$\begin{array}{l}\text { Primary Children's Hospital - Failure Mode and Effect } \\
\text { Analysis } \\
\text { Team Members: }\end{array}$} & \multicolumn{5}{|c|}{$\begin{array}{l}\text { Team Leader: Anya Neidig } \\
\text { Team Facilitator: Mouna Bahsoun }\end{array}$} & \multirow[t]{2}{*}{ Evaluation Due Date: December 2020} \\
\hline & & & & & & \\
\hline Failure Modes & Effects & Severity & Probability & Detection & Hazard Score & $\begin{array}{c}\text { Recommendations or } \\
\text { Actions }\end{array}$ \\
\hline Scanners don't work & & 8 & 7 & 1 & 56 & $\begin{array}{l}\text { Provide education to staff on how to reset scanners: } \\
\text { - How to on every pod } \\
\text { - Train a super user on the unit (HUC) } \\
\text { - Provide extra scanners on pods; keep them charged } \\
\text { - Collaborate with IT to have a contact readily available to troubleshoot on the } \\
\text { unit } \\
\text { - Collaborate with IT to collect data related to scanner shut downs; use data to } \\
\text { make technology recommendations. }\end{array}$ \\
\hline Faded Wristbands/Smeared & & 4 & 7 & 5 & 140 & $\begin{array}{l}\text { Assess for legibility of wristband with off-going nurse during bedside handoff report } \\
\text { and call admitting for new wristband if it is faded/smeared. } \\
\text { Design a redundant plan to make sure wristbands are regularly changed; e.g., } \\
\text { standard day of inpatient days to change wristband. }\end{array}$ \\
\hline Dr. orders Tab but liquid is needed & & 6 & 3 & 8 & 144 & Partner with care transformation to adjust/correct order changes. \\
\hline Absence of Barcode on Meds & & 5 & 3 & 2 & 30 & $\begin{array}{l}\text { Identify } 10 \text { most overridden meds (without barcode) and communicate it every } \\
\text { month to pharmacy (Sabrina) who will be adding meds barcode in the system. }\end{array}$ \\
\hline Meds set up under a different FIN & & 7 & 3 & 6 & 126 & $\begin{array}{l}\text { For chemo orders and transfers from NTU to rehab: } \\
\text { - Merge fins } \\
\text { Design a standardized educational process to new hires within admission to follow } \\
\text { process that has been established by Laura Nicolas. }\end{array}$ \\
\hline Position of Barcode on label & & 5 & 1 & 1 & 5 & Call pharmacy to bring a new label and verify correct med, dose, route, patient \\
\hline $\begin{array}{l}\text { No scanning of controlled substance/double checks } \\
\qquad \mathrm{MRI}\end{array}$ & & 9 & 4 & 5 & 180 & $\begin{array}{l}\text { Redesign workflow; create redundant process. } \\
\text { Create a priority list of caregivers to contact when double checks are needed. }\end{array}$ \\
\hline
\end{tabular}

Abstract 9 Figure 3 Primary children's hospital - failure mode and effect

interprofessional team of nurses, physicians, pharmacists, respiratory therapists, imaging techs and quality professionals. The team came together to conduct a Failure Mode and Effects Analysis (FMEA) and identify units with overrides rates above $2 \%$ to build a task force (figure 3). A nurse manager was identified as the task force leader and every unit was represented by a leader and a worker at the point of care. The task force prioritized addressing knowledge, attitudes and behaviors towards BCMA and applied change concepts to engage the workforce in using the technology. This priority was backed up by availability of weekly data that allowed drilling down to individual measurement of medications administered and BCMA use. Continuous improvement was tracked through run charts that displayed organizational and unit-level results starting with pre-interventions baseline data.

Results A sustained BCMA overrides rate below 2\% was achieved, with a mean of 1.26 (figures 1 and 2).

Conclusions When introducing an interprofessional team to proactive risk assessment and continuous improvement, the
IHI's QI Essentials Toolkit proved effective in providing the team with tools to prioritize efforts, test change, achieve results and sustain improvement over time, all while supporting organizational learning.

\section{CIVIC ENGAGEMENT AS A MEANS TO IMPROVE HEALTH EQUITY}

${ }^{1}$ Aliya Bhatia, ${ }^{2}$ Alister Martin, ${ }^{1}$ Rose Teszler. ${ }^{1}$ Vot-ER; ${ }^{2}$ Massachusetts General Hospital

10.1136/bmjoq-2021-IHI.10

Background Patients' socio-economic, political, and environmental contexts are shaped by public policy. Inequitable public policy creates contexts that lead to poor health. Evidence indicates that those who bear the brunt of health inequities are also most likely to be excluded from the democratic process. Healthcare providers' proximity to marginalized patients and 